\title{
Meiofauna associated with vermetid reefs: the role of macroalgae in increasing habitat size and complexity
}

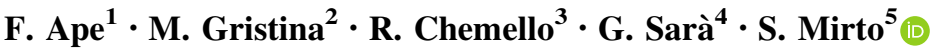

Received: 23 June 2017/ Accepted: 6 July 2018/Published online: 12 July 2018

(C) The Author(s) 2018

\begin{abstract}
We present the first dataset of meiofauna associated with vermetid reefs (biogenic constructions of Mediterranean intertidal habitat) in two areas along the northern coast of Sicily, Italy. The vermetid reefs are characterized by a horizontal extension from the shore towards the open sea and can be divided into three zones (the inner margin, the cuvette zone and the outer margin) which differ in hydrodynamic features. We studied the spatial distribution of meiofauna along the horizontal axis of the vermetid reefs, investigating the communities inhabiting the sediment inside cuvettes (shallow pools inside the "cuvette zone") located between the inner and the outer margins of the reefs. We observed an increase in meiofaunal abundance from the inner to the outer part of the reef (from $1808 \pm 80$ to $2992 \pm 512$ ind. $100 \mathrm{~cm}^{-2}$ ) in
\end{abstract}

Topic Editor Simon Davy

Electronic supplementary material The online version of this article (https://doi.org/10.1007/s00338-018-1714-x) contains supplementary material, which is available to authorized users.

\section{S. Mirto}

simone.mirto@iamc.cnr.it

1 Institute for Coastal Marine Environment, CNR, Via del Mare, 3, 91021 Torretta Granitola - Fraz. Campobello di Mazara, TP, Italy

2 Institute for Coastal Marine Environment, CNR, Via L. Vaccara, 61, 91142 Mazara del Vallo, TP, Italy

3 Dipartimento di Scienze della Terra e del Mare, University of Palermo, via Archirafi 18, 90123 Palermo, Italy

4 Dipartimento di Scienze della Terra e del Mare, University of Palermo, Viale delle Scienze Ed. 16, 90128 Palermo, Italy

5 Institute for Coastal Marine Environment, CNR, Via G. da Verrazzano, 17, 91014 Castellammare del Golfo, TP, Italy both areas. Moreover, we studied meiofaunal communities associated with the most abundant macroalgae (Cystoseira sp., Jania rubens, Palisada perforata, Dictyota sp. and Padina pavonica) living on the reefs, investigating the influence of habitat size (biomass) and identity (complexity) of macroalgae. We found that meiofauna varied in abundance (from $446 \pm 51$ to $1758 \pm 231$ ind. $100 \mathrm{~cm}^{-2}$ on P. perforata and Cystoseira sp., respectively), on different macroalgae, and that the habitat size significantly influenced these abundances, but its effect was dependent on macroalgal identity. In fact, we observed a positive correlation between meiofaunal abundance and algal complexity (fractal dimension). The high algal cover in the "cuvette zone" of the reefs could contribute to make this zone more suitable for meiofauna, in particular close to the outer margin where we found more complex macroalgae (i.e. Cystoseira sp.). These results confirm that vermetid reefs, with their structural complexity, may play an important role in structuring benthic fauna in intertidal habitats.

Keywords Habitat complexity - Biogenic constructions · Meiofaunal community $\cdot$ Mediterranean intertidal habitat

\section{Introduction}

In marine habitats, ecosystem engineers modify the local environment both physically and ecologically, creating a living three-dimensional structure (Jones et al. 1994; Dubois et al. 2002; Gutierrez et al. 2003; Callaway et al. 2010). Habitat complexity is considered to be an important factor influencing the structure of associated communities, providing a wider range of niches for a large and diverse 
group of associated organisms (May 1972; Attrill et al. 2000).

Within rocky intertidal Mediterranean habitats, vermetid reefs represent unique and highly diverse biogenic constructions, structurally comparable to coral fringing reefs in tropical areas (Safriel and Ben-Eliahu 1991; Antonioli et al. 1999). Vermetid reefs are intertidal bioconstructions, built up by gastropod molluscs of the genus Dendropoma in association with some coralline encrusting algae (Safriel 1966). These bioconstructions are of particular ecological and conservation interest because, with their broad and horizontal extension, they represent an amplification of the intertidal zone, supporting many microhabitats (Milazzo et al. 2016). They have a structural role in modifying the shape and ecological characteristics (e.g. limiting physical disturbances, regulating sediment transport, providing refuge from predation and nursery habitat) of the transitional area between mesolittoral and infralittoral rocky flats, creating more complex tridimensional structures and promoting marine biodiversity (Consoli et al. 2008; Colombo et al. 2013; Milazzo et al. 2016). Vermetid reefs can be divided into three morphological zones along a horizontal axis, extending from the shore to the sea: (1) the inner margin, which corresponds to the terrestrial boundary; (2) the "cuvette zone", the central area of the reef with shallow pools named cuvettes located between the inner and the outer margins of the reef; and (3) the outer margin, the sea boundary of the reef (Molinier and Picard 1953; Chemello and Silenzi 2011). These zones differ in hydrodynamic features (such as emersion and wave exposures), creating different microhabitats with distinct populations (Chemello and Silenzi 2011; Chemello et al. 1998; Sarà et al. 2014; Franzitta et al. 2016).

Cuvettes hold water on the flat during low tide and periods of calm seas and are similar to tidal pools in the rocky shore environment (Little et al. 2009; Colombo et al. 2013). Cuvettes are host to macroalgae and encrusting organisms and represent a zone characterized by a high level of habitat complexity and biodiversity (Milazzo et al. 2016).

Vermetid reefs along Sicilian coasts are characterized by several macroalgal species, the most dominant being: Palisada perforata, a red alga that is distributed uniformly along the reef; the brown algae Padina pavonica, Cystoseira spp. and Dictyota spp., mainly present in the "cuvette zone", where corallinales such as Jania rubens are also common (Milazzo et al. 2016). The outer margin, a narrow upper infralittoral fringe, is characterized by Cystoseiradominated assemblages.

Vermetid tubes and reef crevices act as sediment and organic matter traps (Chemello and Silenzi 2011); macroalgae present on the reef have the effect of buffering against wave energy and increasing substrate complexity; therefore, they play an additional role in providing refuge and structure for benthic communities (Danovaro and Fraschetti 2002; Frame et al. 2007; Milazzo et al. 2016).

The information on benthic assemblages inhabiting vermetid reefs is still scant, and many references are sourced from grey literature. Until now, studies concerned with macrobenthic communities such as gastropods (Chemello et al. 1998), polychaetes (Safriel and Ben-Eliahu 1991) and macroalgae (Mannino 1992) revealed high diversity and species abundance at a small scale (i.e. $\mathrm{cu}$ vette scale), and different distributions across the different parts of the reef. Little is known on the role of vermetid reef habitat structure in modifying and influencing the distribution and community composition of meiobenthic communities.

The metazoan meiofauna is a key component of the coastal benthos, contributing to the energy transfer to higher trophic levels and sustaining important ecological processes (Danovaro et al. 2008). Because meiofaunal communities of the intertidal zone are affected by physical constraints of this zone (e.g. temperature variability, emersion, wave action) (Ape et al. 2017), the differences in physical and environmental conditions along the vermetid reefs could influence the distribution of meiofaunal communities, as observed for other organisms (i.e. macrofauna and macroalgae; Safriel and Ben-Eliahu 1991; Mannino 1992; Chemello et al. 1998).

Moreover, in intertidal systems, bioengineers may represent one of the most important determinants in structuring meiofaunal communities (Danovaro and Fraschetti 2002; Kostylev et al. 2005; Bianchelli et al. 2013). In rocky intertidal habitats, the physical structure of macroalgae favours meiofaunal settlement and distribution, reducing sediment agitation, providing refuge from desiccation and increasing substrate complexity (Gibbons 1988; Gee and Warwick 1994; Danovaro and Fraschetti 2002; Frame et al. 2007). The complexity of the phytal habitat is associated with the small-scale variations in shape, size and texture of the algal species (Gee and Warwick 1994). Abundance and diversity of meiofaunal assemblages differ among macroalgal species, generally showing a positive correlation with algal complexity (Gibbons 1988; Gee and Warwick 1994; Veiga et al. 2016).

This study aims to describe meiofaunal communities associated with vermetid reefs along the northern coast of Sicily. Hypothesizing that the distribution of meiofauna varied from the inner to the outer margin of the vermetid reef, we investigated the abundance, diversity (at taxa level) and community composition of meiofauna inhabiting the sediment inside the cuvettes located in different parts of the "cuvette zone" along the horizontal axis of the reefs.

Moreover, to test the idea that macroalgae may increase the size and complexity of the substrate suitable for 
meiofauna organisms on the vermetid reef, we explored the differences in the meiofaunal community associated with five macroalgae (Palisada perforata, Padina pavonica, Jania rubens, Dyctiota sp. and Cystoseira sp.) living on the reefs. We hypothesized (1) that the meiofaunal abundance and community structure will be affected by the habitat size (i.e. biomass) provided by macroalgae and (2) that apart from the effect of habitat size, the identity of macroalgae (with different complexity) could play a significant role in shaping the abundance and the community structure of meiofauna living on the reef.

\section{Materials and methods}

\section{Study areas}

The study was carried out along the northern coast of Sicily (Italy), where large vermetid reefs are commonly found (Chemello and Silenzi 2011; Milazzo et al. 2016). We investigated two coastal rocky areas (Fig. 1a) characterized by the presence of vermetid reefs, of comparable dimensions (total horizontal width $\sim 6-7 \mathrm{~m}$; width of inner margin $\sim 30-40 \mathrm{~cm}$, and few centimetres thick; outer margin width $\sim 50-70 \mathrm{~cm}$; depth of $\mathrm{cu}$ vettes 30-40 cm; Badalamenti et al. 1992; Antonioli et al. 1999; Chemello and Silenzi 2011; Balistreri et al. 2015). The study areas were: (1) Capo Gallo, at the westernmost limit of the Gulf of Palermo $\left(38^{\circ} 12^{\prime} 38^{\prime \prime} \mathrm{N}\right.$; $13^{\circ} 17^{\prime} 13^{\prime \prime} \mathrm{E}$ ), inside the marine protected area (MPA) "Capo Gallo-Isola delle Femmine"; and (2) Favignana Island $\left(37^{\circ} 56^{\prime} 50^{\prime \prime} \mathrm{N}, 12^{\circ} 17^{\prime} 51^{\prime \prime} \mathrm{E}\right)$ within the marine protected area (MPA) "Egadi Islands", where we sampled on a vermetid reef located along the northern side of the island.

Both areas are subjected to the same tidal regime and are exposed to similar winds (north and north/west) and wave action (Badalamenti et al. 1992; Antonioli et al. 1999; Balistreri et al. 2015).

Sampling was carried out in October 2014, in calm water and under low tide. In each area, two horizontal transects of vermetid reef were investigated to study the meiofaunal communities living in the sediment deposited inside the cuvettes and those associated with the most characteristic macroalgae taxa present on the reefs.

\section{Experimental assumptions and design}

In order to study the distribution of meiobenthic organisms along the horizontal axis (shore-sea) of the vermetid reef, we sampled meiofauna inside the cuvettes, where fine sandy sediment can be deposited (Chemello and Silenzi 2011). Sediment samples were collected in the "cuvette zones" from cuvettes located: (1) close to the inner margin; (2) in the middle of the "cuvette zone"; and (3) close to the outer margin of the vermetid reef (Fig. 1b).

To investigate the meiofaunal communities associated with macroalgae colonizing the vermetid reef, we carried out a preliminary survey (1 month before sampling) to assess the coverage $(\%)$ of macroalgae colonizing the inner margin, central "cuvette zone", and the outer margin of the selected vermetid reefs (Capo Gallo and Favignana Island). The macroalgal coverage was visually estimated, using a plastic frame $20 \mathrm{~cm} \times 20 \mathrm{~cm}$ in size $(n=5)$, randomly placed on each sampling location (Di Franco et al. 2011).

We found similar total macroalgae coverage on the reefs of both study areas: $\sim 40 \%$ on the inner margin; $\sim 80 \%$ on the "cuvette zone"; and $\sim 60 \%$ on the outer margin; with the remaining percentage represented by vermetid complex (Dendropoma cristatum and Neogoniolithon sp.) and bare rocky substrate. Because we found that Palisada perforata, Padina pavonica, Jania rubens, Dyctiota sp. and Cystoseira sp. were the most abundant macroalgae, according to the literature (Mannino 1992; Milazzo et al. 2016), at the sampling time (in October) we investigated meiofaunal communities associated with these macroalgal taxa. Because the coverage of the investigated macroalgae varied along the vermetid reefs, we sampled each macroalgae where it was more abundant and formed homogeneous and single-taxa patches. Some macroalgae were sampled only in one of the two vermetid horizontal transects in each areas because we have not always found homogeneous and single-taxa patches. Moreover, the macroalga $P$. pavonica was sampled only at Favignana Island because it was not found as homogeneous patches at the Capo Gallo reefs during the sampling period. Considering that the complexity of phytal habitat may differ among the investigated macroalgae, and this in turn could affect the abundance and community structure of the associated meiofauna (Gibbons 1988; Gee and Warwick 1994; Veiga et al. 2016), we estimated algal architecture (in terms of habitat size and complexity) of the five most abundant macroalgal taxa and we correlated it with meiofaunal taxa abundances.

\section{Sample collection}

Three randomly chosen sediment samples were manually collected in each cuvette located in the three positions (3 replicates $\times 3$ positions $\times 2$ horizontal transects in each area; Fig. 1b), scraping a thin layer of sediment $(1 \mathrm{~cm}$ thick inside quadrates of $10 \mathrm{~cm} \times 10 \mathrm{~cm}$ ), collecting it using a syringe to reduce "washing" of the sediment by the overlying water. The sediment was fixed in $4 \%$ buffered formaldehyde in filtered $(0.4 \mu \mathrm{m})$ seawater solution until laboratory meiofauna analyses could be performed. 


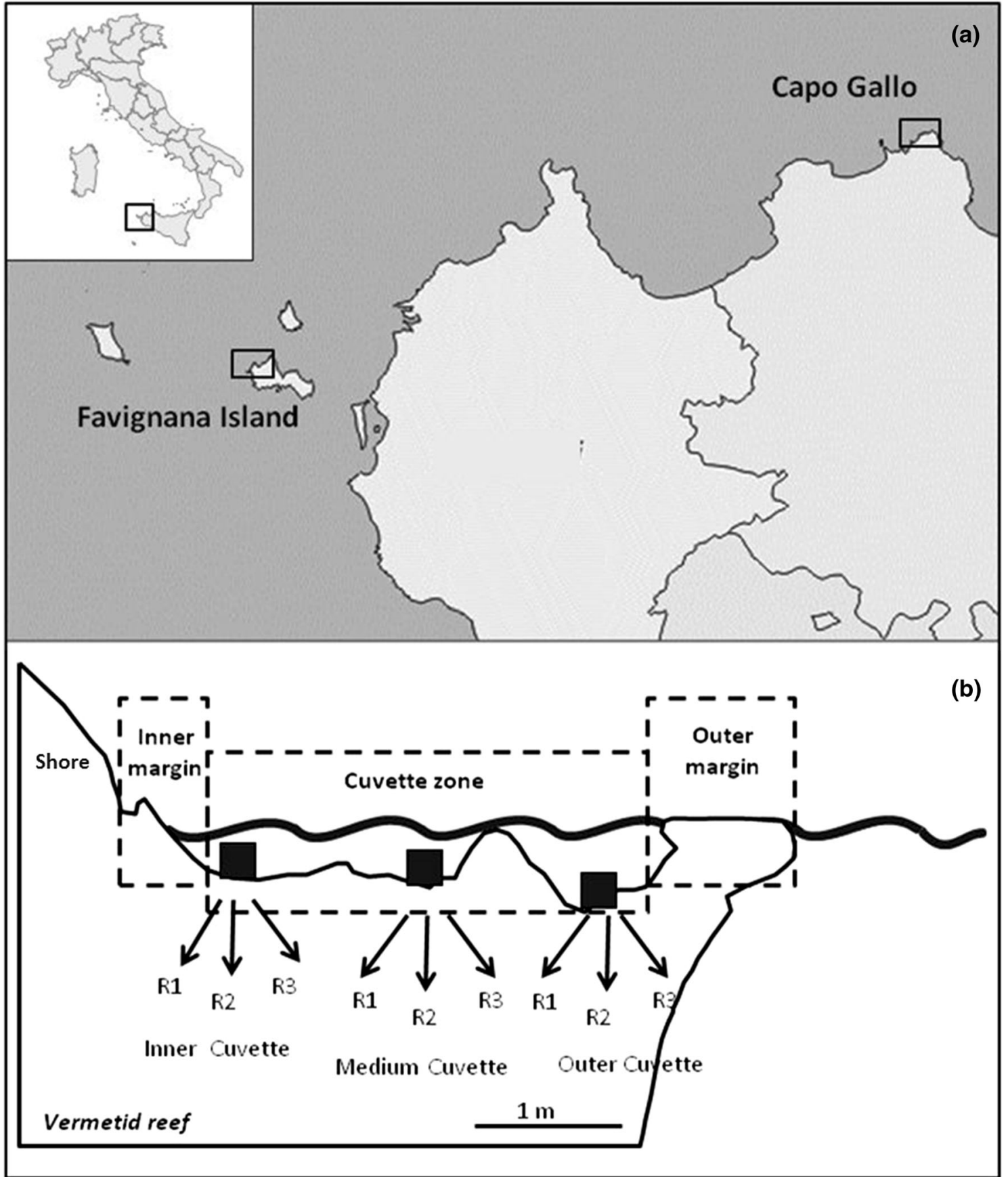

Fig. 1 a Sampling areas (Favignana Island and Capo Gallo) and b sampling strategy along the investigated vermetid reef. Here we indicate the positions of the cuvettes where we collected the sediment

To analyse meiofauna associated with macroalgae taxa, macroalgal patches were entirely scraped from three randomly chosen quadrates $(10 \mathrm{~cm} \times 10 \mathrm{~cm})$ and carefully and quickly placed into plastic bags to avoid the loss of organisms. These samples ( 3 replicates $\times 5$ macroalgae taxa $\times 2$ horizontal transects in each area) were preserved in $4 \%$ buffered formaldehyde in filtered $(0.4 \mu \mathrm{m})$ seawater solution and were brought back to the laboratory for analysis. samples: close to inner margin (inner), in the middle of the "cuvette zone" (medium) and close to outer margin (outer)

\section{Meiofauna analysis}

Meiofauna sediment samples were sieved through a $37 \mu \mathrm{m}$ mesh, after a previous sieving through $1 \mathrm{~mm}$ mesh to exclude larger organisms. The fraction retained on the sieve was resuspended and centrifuged three times with Ludox HS40 (diluted with water to a final density of $1.18 \mathrm{~g} \mathrm{~cm}^{-3}$; Heip et al. 1985). The material collected was 
preserved in 50-ml tubes with $4 \%$ buffered formalin and stained with Rose Bengal $\left(0.5 \mathrm{~g} \mathrm{l}^{-1}\right)$.

To extract meiofaunal organisms from macroalgae, the samples were washed in freshwater and shaken vigorously several times to remove the meiofauna, which were extracted by decantation and sieved through a $37 \mu \mathrm{m}$ mesh (Gee and Warwick 1994), after a previous sieving through $1 \mathrm{~mm}$ mesh. This procedure was repeated ten times for each sample. The fraction retained on the sieve was preserved in 50-ml tubes with $4 \%$ buffered formalin and stained with Rose Bengal (0.5 $\left.\mathrm{g} \mathrm{l}^{-1}\right)$. Meiobenthic organisms were counted and classified at the major taxa level of taxonomic discrimination using a stereomicroscope. The abundance of total meiofauna and of single taxa was reported to the surface unit $(10 \mathrm{~cm} \times 10 \mathrm{~cm}$ area $=100 \mathrm{~cm}^{2}$ ) both for the sediment samples and for macroalgae patches.

\section{Macroalgal architecture}

We measured the habitat architecture using biomass and fractal dimension of macroalgae as proxies for habitat size and habitat complexity, respectively (Gee and Warwick 1994; Hooper and Davenport 2006; Veiga et al. 2016). Macroalgae were dried (for $48 \mathrm{~h}$ at $60{ }^{\circ} \mathrm{C}$ ) and weighed to determine the biomass in a $100 \mathrm{~cm}^{2}$ area, expressed in grams of dry weight (DW).

To calculate the fractal dimensions, a branch (3 replicates from each quadrate) of each macroalga was photographed with a Nikon Coolpix S2600 digital camera. Fractal dimensions were calculated following procedures described by McAbendroth et al. (2005). Each resulting TIFF image was converted to grayscale mode and a threshold was set to produce a binary image that was used to quantify the fractal dimensions (i.e. complexity) of area (DA) and perimeter (DP) for each image, by using the Image J software (Rasband 1997). The DA is an estimate of area occupancy indicating how the perception of surface area might change with scale. The DP is an estimate of edge complexity, relating to the nature of the gaps between the macroalgal parts (McAbendroth et al. 2005; Veiga et al. 2014). Due to the small size of meiofauna (ranging from $30 \mu \mathrm{m}$ to $1 \mathrm{~mm}$; Mare 1942), complexity parameters of a branch of macroalga were considered an appropriate scale in structuring the physical environment at the complexity perception of our target organisms (Attrill et al. 2000; Veiga et al. 2016).

\section{Statistical analysis}

To test differences along the horizontal axis of the vermetid reefs, univariate and multivariate distance-based permutational nonparametric analyses of variance (PERMANOVA;
Anderson 2001; McArdle and Anderson 2001) were performed on total abundance, taxa richness and communities composition of meiofauna in the sediment inside the $\mathrm{cu}$ vettes, including study areas (two levels: Capo Gallo and Favignana Island) and positions in the "cuvette zone" (three levels: inner, medium and outer) as fixed factors. PERMANOVAs were based on Bray-Curtis similarity matrices after square root transformation of the data using 9999 permutations under unrestricted permutations of the raw data (univariate tests) or under a reduced model (multivariate test) with a Type III (partial) sum of squares (Anderson 2001).

PERMANOVA was also performed to test the hypotheses that the habitat size (biomass) and complexity (DA and DP) and associated meiofauna communities (abundance, the taxa richness and the structure) differed among macroalgae (fixed factor with five levels: $P$. perforata, P. pavonica, J. rubens, Dictyota sp. and Cystoseira sp.), colonizing the reefs in both sampling areas (fixed factor with two levels: Capo Gallo and Favignana Island).

According to the method used by Veiga et al. (2016), to investigate the influence of habitat size (i.e. algal biomass) on meiofaunal parameters we used biomass as the covariate. Interactions between the factors and the covariate were included in the analyses. The calculation of the significance of the factors, by subtracting the effect of the covariate (i.e. biomass), allows us to test the effect of macroalgal taxa of different complexity independently of the biomass. PERMANOVAs were based on Bray-Curtis similarity matrices after square root transformation of the data (meiofaunal parameters) or Euclidean distance matrices calculated on normalized data (biomass and fractal measures). In the analysis with a covariate we used 9999 permutations under a reduced model with the Type I (sequential) sum of squares (Anderson 2001).

When we found significant differences, a pairwise comparison was done to explore differences among all pairs of levels of the selected factor (i.e. position and macroalgae), including biomass as the covariate where necessary. Because of the restricted number of unique permutations in the pairwise tests, $p$ values were obtained from Monte Carlo samplings (Anderson and Robinson 2003).

To test the null hypothesis of equal dispersions among the two areas for both analysis (sediments and macroalgae), we also used a test of homogeneity of dispersion (PERMDISP). Since the PERMDISP analysis reveals no significant differences in the multivariate dispersion, results are not reported.

Moreover, SIMPER analyses were performed on matrices of Bray-Curtis similarities, constructed on previously square-root-transformed data, to assess the percentage dissimilarity in meiofaunal community composition both between the three positions and among 
different macroalgae and to identify which of the investigated taxa was most responsible for the observed dissimilarities.

Statistical analyses were performed using the PRIMER v6+ software (Plymouth Marine Laboratory; Clarke 1993; Clarke and Warwick 1994).

To investigate which measures of macroalgal architecture can influence the distribution of the abundance of total meiofauna and of the most abundant taxa (i.e. copepods and nematodes), linear regressions (Statistica 6.0, StatSoft) between habitat size and complexity of macroalgae (DP and DA) and meiofauna abundances (square-root-transformed data) were tested for significance. Because we detected no significant differences between the two study areas in meiofaunal abundance, we performed the regression analysis on pooled data.

\section{Results}

\section{Meiofauna in the cuvettes sediments}

Our results showed that the total meiofaunal abundance significantly varied along the horizontal axis of vermetid reefs (PERMANOVA, $p<0.001$; ESM Table 1). Pairwise comparisons, performed comparing the three positions (ESM Table 2), revealed significantly higher values of total meiofaunal abundance inside the cuvettes located close to the outer margin than those found in the other two positions (mean between the two areas in each position $\pm \mathrm{SE}$; Fig. 2). We also found significant differences in taxa richness when comparing cuvettes located along the horizontal axis of the reefs (PERMANOVA, $p<0.01$; ESM Table 1); however, we also observed significant differences between the sampling areas $(p<0.01)$. The values of taxa richness and of the meiofaunal abundance are reported in Table 1.

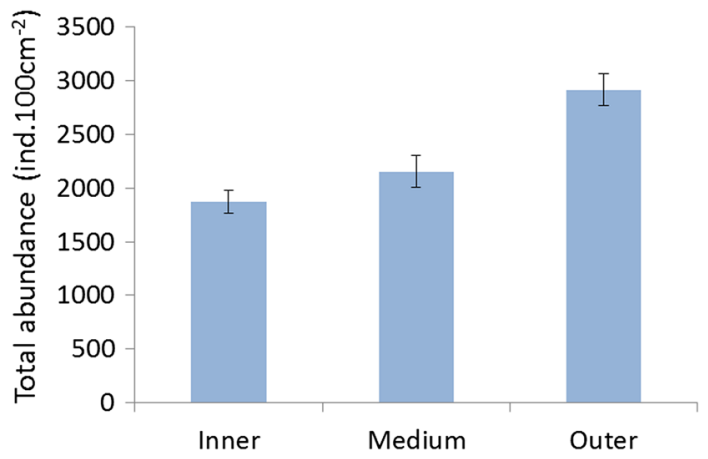

Fig. 2 Total meiofauna abundance in the sediment inside the cuvettes located: close to the inner margin; in the middle of the "cuvette zone"; and close to the outer margin (mean between the two areas in each position $\pm \mathrm{SE})$
The communities were dominated by copepods (ranging from $62 \%$ close to the inner margin to $73 \%$ close to the outer margin), followed by nematodes (ranging from $15 \%$ close to the outer margin to $20 \%$ close to the inner margin). Following copepods and nematodes, the next most abundant taxa were polychaetes, ostracods, amphipods, isopods, turbellaries and tanaids (mean between the two areas in each position; Fig. 3). The less abundant taxa, with percentage lower than $0.5 \%$, were pooled into a single category named "others".

PERMANOVA showed significant differences in meiofaunal community composition among the different cuvette positions ( $p<0.001$; ESM Table 1). SIMPER analyses revealed that dissimilarity in meiofaunal communities between the three positions in the "cuvette zone" was mostly explained by the abundance of copepods, the most abundant taxon (from 20 to $30 \%$ of total dissimilarity; Table 2). In fact, while nematodes showed no significant difference in abundance along the horizontal axis of vermetid reefs (PERMANOVA, $p=$ n.s.; ESM Table 1), total crustaceans (copepods, ostracods, amphipods, isopods and tanaids), copepods in particular, showed significantly higher values inside the cuvettes close to the outer margin than those in cuvettes located in the inner zone (pairwise $p<0.001$ ESM Table 2).

\section{Meiofauna associated with macroalgae}

PERMANOVA showed a significant effect of habitat size (i.e. biomass) and macroalgal identity on total abundance of meiofauna associated to the different taxa of macroalgae ( $p<0.001$; ESM Table 3). Moreover, habitat size showed a significant interaction with macroalgal identity, indicating that the effect of habitat size was different among macroalgae.

Pairwise comparisons among macroalgae (ESM Table 4) showed generally significant differences. We observed that the meiofaunal abundance associated with Cystoseira sp. was significantly higher (pairwise $p<0.01$ ) with respect to the other algae (mean between the two areas on each macroalga \pm SE; Fig. 4). Taxa richness showed not significant differences among macroalgal taxa (PERMANOVA; ESM Table 3). The values of taxa richness and of the meiofaunal abundance on the five macroalgae taxa are reported in Table 3.

Despite finding significant differences between the two areas in meiofaunal community composition (PERMANOVA, $p<0.001)$, in both areas communities associated with all macroalgae were dominated by copepods, representing more of $50 \%$ of the total abundance, followed by nematodes (ranging in mean from 20 to 26\%). Following these taxa were polychaetes, amphipods, acari, isopods, ostracods, gasteropods, tanaids and "other" taxa, 
Table 1 Taxa richness, abundance of total meiofauna and of single meiofaunal taxon (ind. $100 \mathrm{~cm}^{-2}$ ) in the sediment inside the cuvettes located close the inner margin, in the middle of the "cuvette zone" and close the outer margin at Capo Gallo and Favignana (mean between the two sampled reefs in each area \pm SE)

\begin{tabular}{|c|c|c|c|c|c|c|}
\hline \multirow[t]{2}{*}{ Taxa } & \multicolumn{3}{|l|}{ Capo Gallo } & \multicolumn{3}{|l|}{ Favignana } \\
\hline & Inner & Medium & Outer & Inner & Medium & Outer \\
\hline Nematoda & $438.5 \pm 211.5$ & $440.7 \pm 268.7$ & $618.5 \pm 120.5$ & $311.0 \pm 42.3$ & $243.0 \pm 3.0$ & $250.3 \pm 40.3$ \\
\hline Copepoda & $1102.7 \pm 319.3$ & $1331.0 \pm 12.3$ & $1808.0 \pm 2.0$ & $1244.7 \pm 123.3$ & $1677.7 \pm 171.6$ & $2450.5 \pm 355.5$ \\
\hline Polychaeta & $103.8 \pm 4.8$ & $104.3 \pm 22.3$ & $184.0 \pm 4.0$ & $274.7 \pm 76.0$ & $258.8 \pm 73.8$ & $220.0 \pm 120.0$ \\
\hline Ostracoda & $67.3 \pm 18.6$ & $85.3 \pm 36.7$ & $93.0 \pm 0.0$ & $74.0 \pm 48.0$ & $32.3 \pm 3.7$ & $26.8 \pm 5.8$ \\
\hline Kinorincha & 0.0 & 0.0 & $0.5 \pm 0.5$ & 0.0 & $1.7 \pm 0.3$ & 0.0 \\
\hline Turbellaria & $16.2 \pm 15.2$ & $12.7 \pm 8.0$ & $11.0 \pm 1.0$ & $3.7 \pm 3.7$ & $9.7 \pm 9.7$ & 0.0 \\
\hline Tardigrada & 0.0 & 0.0 & 0.0 & 0.0 & $0.7 \pm 0.7$ & 0.0 \\
\hline Gastrotricha & $0.5 \pm 0.5$ & 0.0 & 0.0 & 0.0 & 0.0 & 0.0 \\
\hline Amphipoda & $37.5 \pm 12.5$ & $27.0 \pm 1.7$ & $39.0 \pm 6.0$ & $18.0 \pm 3.3$ & $18.2 \pm 9.2$ & $29.3 \pm 0.7$ \\
\hline Isopoda & $22.7 \pm 6.7$ & $40.0 \pm 14.0$ & $58.5 \pm 15.5$ & $15.7 \pm 0.3$ & $6.2 \pm 3.2$ & $14.7 \pm 9.3$ \\
\hline Tanaidacea & $9.0 \pm 3.0$ & $10.7 \pm 1.3$ & $25.5 \pm 5.5$ & 0.0 & $3.3 \pm 3.3$ & $0.7 \pm 0.7$ \\
\hline Acarina & $7.2 \pm 2.2$ & $4.3 \pm 2.3$ & $3.5 \pm 2.5$ & 0.0 & 0.0 & 0.0 \\
\hline Picnogonida & 0.0 & $0.7 \pm 0.0$ & 0.0 & 0.0 & 0.0 & 0.0 \\
\hline Gastropoda & $2.3 \pm 2.3$ & $0.7 \pm 0.7$ & $1.0 \pm 1.0$ & 0.0 & 0.0 & 0.0 \\
\hline Total abundance & $1807.7 \pm 80.3$ & $2057.3 \pm 368.0$ & $2842.5 \pm 143.5$ & $1941.7 \pm 290.3$ & $2252.2 \pm 265.2$ & $2992.3 \pm 512.3$ \\
\hline Richness & $9.1 \pm 0.6$ & $9.5 \pm 0.5$ & $9.0 \pm 0.0$ & $6.0 \pm 0.0$ & $8.2 \pm 1.2$ & $5.8 \pm 0.2$ \\
\hline
\end{tabular}

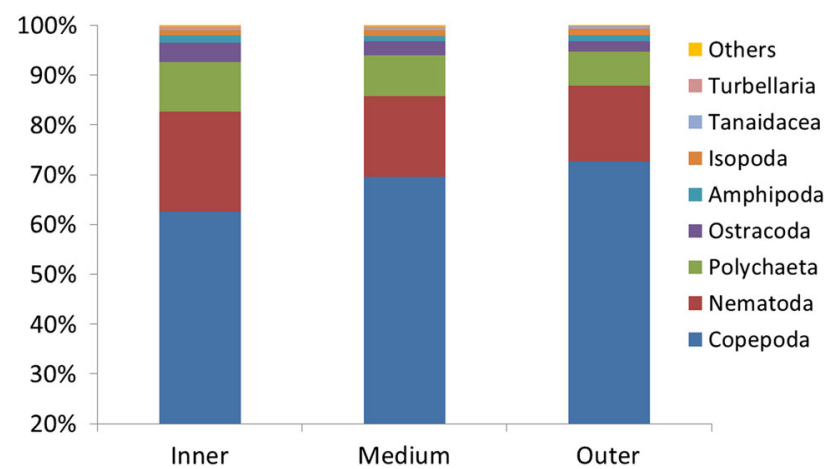

Fig. 3 Meiofauna community structure in the sediment inside the cuvettes located: close to the inner margin; in the middle of the "cuvette zone"; and close to the outer margin (mean between the two areas in each position $\pm \mathrm{SE}$ )

representing $<0.5 \%$ of total abundance (mean between the two areas on each macroalgae; Fig. 5).

Meiofaunal community composition significantly varied among different macroalgae (PERMANOVA, $p<0.001$; ESM Table 3). These significant differences were mostly explained by the abundance of copepods (SIMPER up to $30 \%$ of total dissimilarity), representing the most abundant taxon (Table 4). The abundance of crustaceans (copepods, ostracods, amphipods, isopods, and tanaids), particularly copepods, was significantly higher on Cystoseira $\mathrm{sp}$. than on the other macroalgae (pairwise, $p<0.01$; ESM Table 4).

\section{Macroalgal coverage and architecture}

During the survey we found on the inner margin only $P$. perforata $(13 \pm 1.8 \%)$ and Dictyota $\mathrm{sp} .(8 \pm 0.3 \%)$, while Dictyota sp. $(38 \pm 3.4 \%)$ dominated in the central "cuvette zone" followed by $P$. pavonica $(18 \pm 3.1 \%)$, J. rubens $(7 \pm 1.7 \%)$, P. perforata $(5 \pm 0.9 \%)$ and Cystoseira sp. $(4 \pm 0.9 \%)$. On the outer margin, the dominant macroalga was Cystoseira sp. $(20 \pm 4.0 \%)$ followed by Dictyota sp. $(15 \pm 2.1 \%), P$. perforata $(12 \pm 2.6 \%)$ and $J$. rubens $(2 \pm 0.3 \%)$.

In Table 5 we report the values of biomass and fractal dimension (DA and DP) of the studied macroalgae. PERMANOVA analysis (ESM Table 5) showed that macroalgal taxa significantly differed in both biomass $(p<0.001)$ and fractal dimension $(p<0.001$. Pairwise comparisons performed among macroalgae (ESM Table 6) showed that the biomass of Cystoseira sp. was significantly higher $(p<0.01)$ than that of other macroalgae, followed by $J$. rubens. Values of the macroalgal DA and DP differed significantly between macroalgal taxa (PERMANOVA, $p<0.001$; ESM Table 5). J. rubens and P. pavonica showed significantly higher DA (pairwise, $p<0.001$ ), while Cystoseira sp. and J. rubens were more complex according to DP (pairwise, $p<0.001$; ESM Table 6).

Regression analysis performed on pooled data, to investigate the relationship between macroalgal architecture and meiofauna, showed that the meiofaunal abundance 
Table 2 Output of the SIMPER analyses and PERMANOVA pairwise carried out on meiofaunal community composition in the sediment inside the cuvettes

\begin{tabular}{lllcc}
\hline & SIMPER & & $\frac{2}{\text { PERMANOVA pairwise }}$ \\
& \% Dissimilarity & & $t$ \\
\hline Group & & & P (MC) \\
Inner versus medium & 18.5 & Copepoda (20\%), Nematoda (18\%), Polychaeta (15\%), Ostracoda (10\%) & 1.24 & n.s. \\
Inner versus outer & 19.7 & Copepoda (33\%), Nematoda (16\%), Polychaeta (12\%) & 2.86 & $* * *$ \\
Medium versus outer & 18.1 & Copepoda (23\%), Nematoda (18\%), Polychaeta (14\%), Isopoda (10\%) & 2.18 & $* *$
\end{tabular}

The meiofaunal taxa included in this table were responsible of $60 \%$ cumulative dissimilarity among the different positions (close the inner margin, in the middle of the "cuvette zone" and close the outer margin) at Capo Gallo and Favignana

$\mathrm{P}(\mathrm{MC})=$ probability level; n.s. $=$ not significant

$* * * p<0.001 ; * * p<0.01 ; * p<0.05$

Fig. 4 Total meiofauna abundance associated with the five investigated macroalgae taxa (Palisada perforata,

Padina pavonica, Jania rubens, Dictyota sp. and Cystoseira sp.) colonizing the vermetid reefs each macroalga \pm SE) (mean between the two areas on

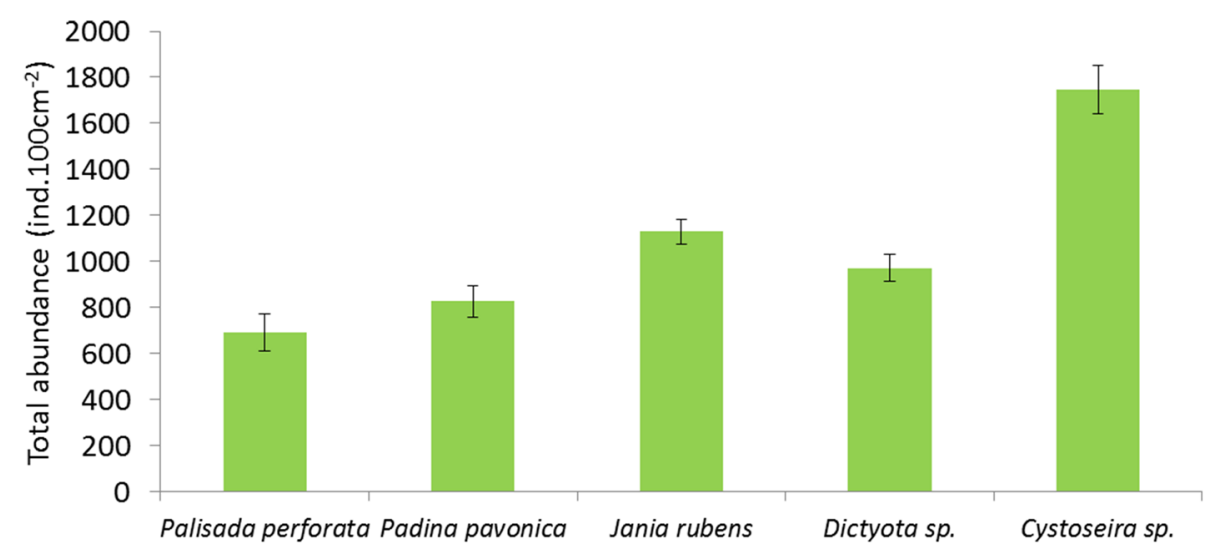

was significantly positively correlated with algal biomass and DP and not with DA (Fig. 6a). We found the same trend for the abundance of nematodes and copepods, the two dominant taxa (Fig. 6b, c). We report $\mathrm{R}$ and $\mathrm{P}$ values of regressions in Fig. 6.

\section{Discussion}

Vermetid reef are biogenic constructions that, thanks to their horizontal extension (from the upper mesolittoral area to the infralittoral fringe) and their spatial complexity, play a key role in modulating morphological coastal processes and in structuring associated communities (Chemello and Silenzi 2011; Di Franco et al. 2011; Milazzo et al. 2016).

Residual water, particulate organic matter and sediment are often trapped between the reef rims and inside the cuvettes (Milazzo et al. 2016), making the substrate suitable for the settlement of meiofaunal communities. In fact in this study we found, in the sediments collected from cuvettes on the investigated reefs, values of meiofauna abundance comparable or higher than those reported in sediments associated with coral reefs and coral colonies (Logan et al. 2008; Cerrano et al. 2010). We observed a significant increase in meiofaunal density inside cuvettes, from the inner to the outer margin of the reefs. The studies on benthic assemblages inhabiting Mediterranean vermetid reefs, many of which are derived from grey literature, revealed high abundance and diversity of species at a small scale (i.e. cuvette scale) compared to other rocky intertidal habitats (Mannino 1992; Chemello et al. 1998; Goren and Galil 2001). The different sections of the vermetid reef are characterized by physical and environmental differences that give the microhabitat different features (Chemello and Silenzi 2011; Vizzini et al. 2012). The inner margin is the zone most exposed to emersion periods during low tide, desiccation and thermal stress in the warmer months, whereas the outer margin is the zone most exposed to wave action and to the input of allochthonous resources from the adjoining open sea (Chemello and Silenzi 2011; Vizzini et al. 2012). These physical conditions along the vermetid reef could explain the higher abundance of meiofauna observed inside the cuvettes close to the outer margins, where the organisms could find more suitable living conditions with regard to water temperature and input of trophic resources (i.e. allochthonous organic matter). Consistent with our results, Chemello et al. (1998) found higher abundance and diversity (number of species) of 


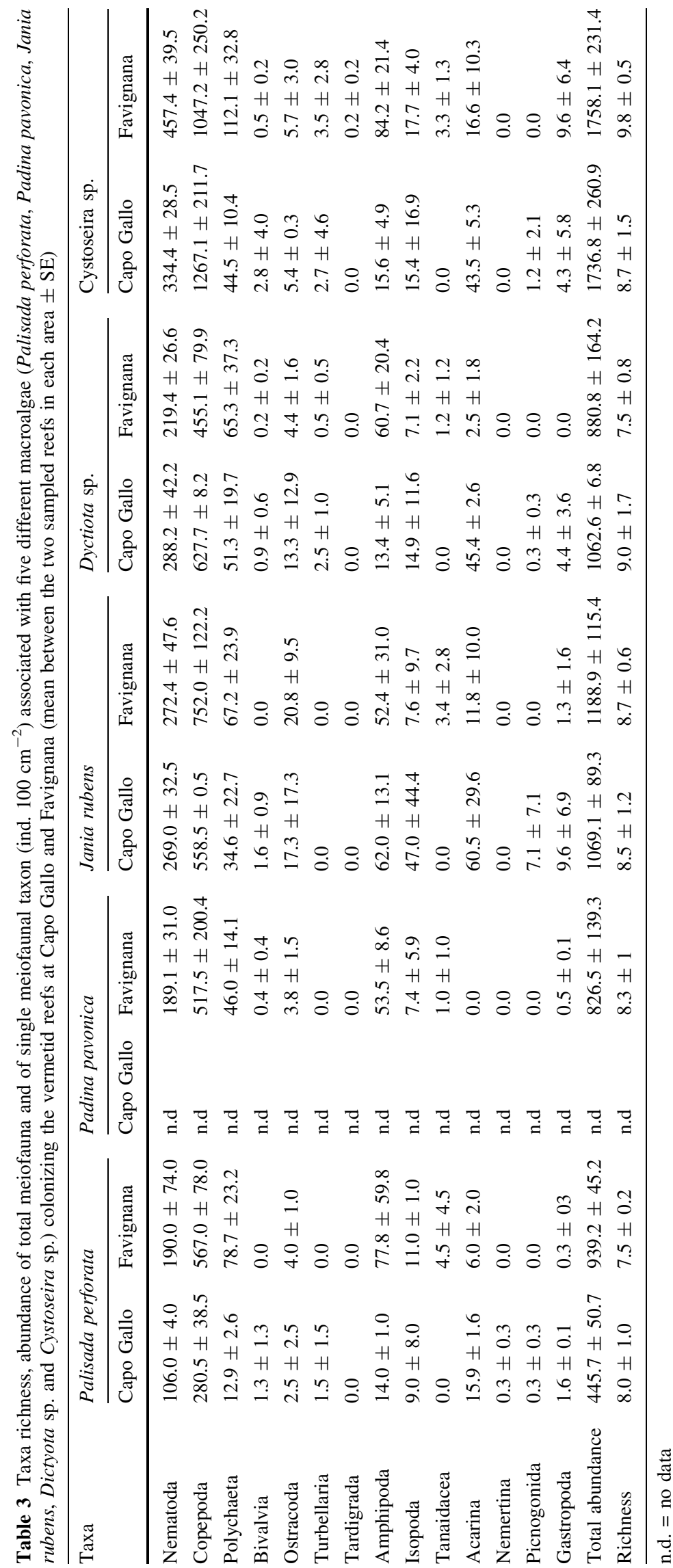


Fig. 5 Meiofauna community structure associated with the five investigated macroalgae taxa (Palisada perforata, Padina pavonica, Jania rubens, Dictyota sp. and Cystoseira sp.) colonizing the vermetid reefs (mean between the two areas on each macroalga $\pm \mathrm{SE}$ )

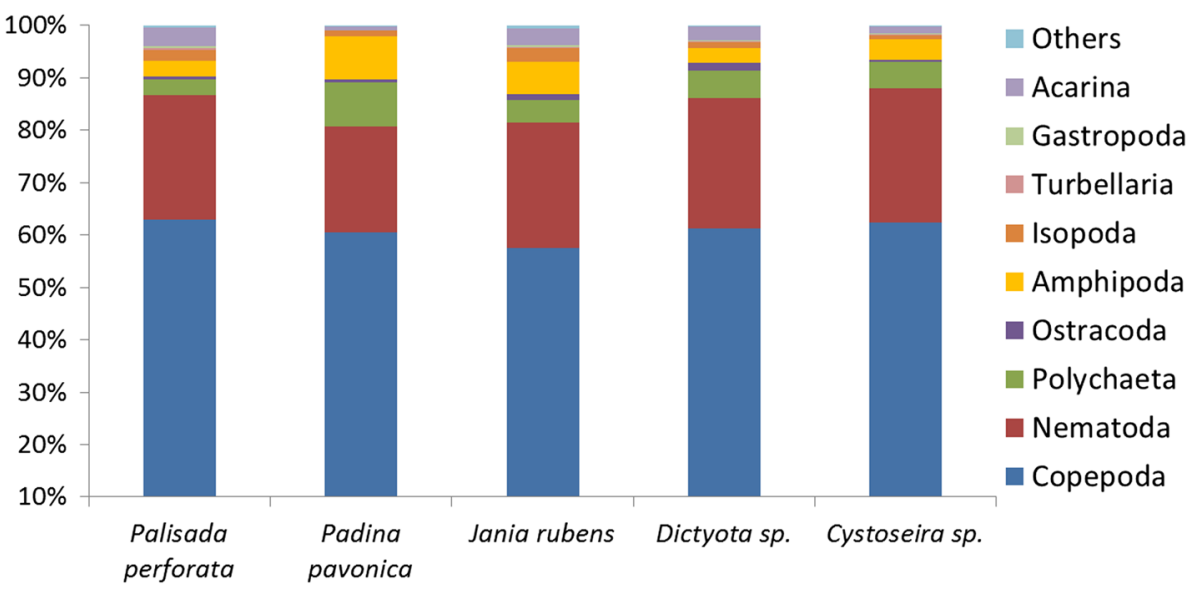

Table 4 Output of the SIMPER analyses and PERMANOVA pair wise (with biomass as covariate) carried out on meiofaunal community composition associated to macroalgae

\section{SIMPER \\ $\%$ \\ Dissimilarity}

PERMANOVA pairwise

$t \quad \mathrm{P}(\mathrm{MC})$

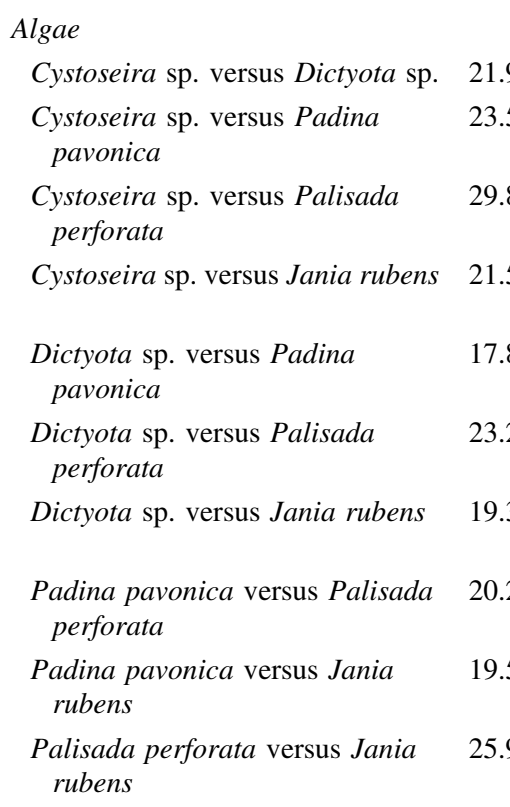

Copepoda (31\%), Nematoda (12\%), Amphipoda (11\%), Acarina (9\%) $2.9 \quad * *$

Copepoda (32\%), Nematoda (20\%), Amphipoda (8\%), Polychaeta (8\%) $3.1 \quad * * *$

Copepoda (32\%), Nematoda (21\%), Polychaeta (10\%)

$2.6 *$

Copepoda (25\%), Nematoda (12\%), Polychaeta (10\%), Isopoda (10\%), $1.8 \quad *$ Acarina (9\%)

Nematoda (17\%), Copepoda (17\%), Amphipoda (14\%), Acarina (13\%), $1.0 \quad$ ** Polychaeta $(9 \%)$

Nematoda (20\%), Copepoda (18\%), Amphipoda (12\%), Polychaeta 1.1 *** $(12 \%)$

Acarina (14\%), Copepoda (12\%), Isopoda (12\%), Amphipoda (12\%), $1.6 \quad *$ Ostracoda (10\%)

Copepoda (22\%), Amphipoda (16\%) Nematoda (26\%), Polychaeta 0.9 ** $(13 \%)$

Copepoda (15\%), Acarina (15\%) Isopoda (13\%), Ostracoda (11\%), $\quad 1.5 \quad *$ Nematoda (11\%)

Copepoda (18\%), Nematoda (15\%), Amphipoda (12\%), Acarina (11\%), $1.2 \quad * *$ Isopoda (10\%)

The meiofaunal taxa included in this table were responsible of $60 \%$ cumulative dissimilarity among the five different macroalgae (Palisada sp., Padina pavonica, Jania rubens, Dictyota sp. and Cystoseira sp.) colonizing the vermetid reefs at Capo Gallo and Favignana

$\mathrm{P}(\mathrm{MC})=$ probability level; n.s. $=$ not significant

*** $p<0.001 ; * * p<0.01 ; * p<0.05$

macrobenthic gastropods on the outer margin of the vermetid reefs at Capo Gallo, highlighting that the distribution patterns of organisms reflected their hydrodynamic tolerance. The richness of taxa showed no significant difference along the investigated reefs. We observed significant differences in meiofaunal community composition among the different cuvettes positions. However, because of the high abundance of copepods and nematodes, these differences were probably the result of differing abundance of these taxa between the compared samples rather than real changes in the composition of the community. In fact we observed that the differences among cuvette position were mostly explained by copepod abundance. We found that crustaceans, namely copepods, were significantly more 
Table 5 Habitat size (biomass expressed in gDW) and complexity, expressed as fractal dimension of area (DA) and perimeter (DP) of the five different macroalgae (Palisada perforata, Padina pavonica,
Jania rubens, Dictyota sp. and Cystoseira sp.) colonizing the vermetid reefs at Capo Gallo and Favignana (mean between the two sampled reefs in each area \pm SD)

\begin{tabular}{|c|c|c|c|c|c|}
\hline Algal architecture & Palisada perforata & Padina pavonica & Jania rubens & Dyctiota $\mathrm{sp.}$ & Cystoseira sp. \\
\hline \multicolumn{6}{|l|}{ Capo Gallo } \\
\hline Biomass & $0.68 \pm 0.05$ & n.d & $3.85 \pm 0.13$ & $2.49 \pm 0.30$ & $4.65 \pm 0.29$ \\
\hline DA & $1.82 \pm 0.01$ & n.d & $1.91 \pm 0.01$ & $1.78 \pm 0.01$ & $1.85 \pm 0.02$ \\
\hline DP & $1.14 \pm 0.00$ & n.d & $1.20 \pm 0.02$ & $1.12 \pm 0.00$ & $1.23 \pm 0.00$ \\
\hline \multicolumn{6}{|l|}{ Favignana } \\
\hline Biomass & $1.90 \pm 0.12$ & $4.08 \pm 0.42$ & $6.32 \pm 0.29$ & $2.93 \pm 0.25$ & $7.29 \pm 0.70$ \\
\hline DA & $1.85 \pm 0.01$ & $1.91 \pm 0.10$ & $1.91 \pm 0.00$ & $1.79 \pm 0.01$ & $1.87 \pm 0.01$ \\
\hline DP & $1.13 \pm 0.02$ & $1.05 \pm 0.02$ & $1.19 \pm 0.00$ & $1.10 \pm 0.02$ & $1.21 \pm 0.01$ \\
\hline
\end{tabular}

n.d. = no data
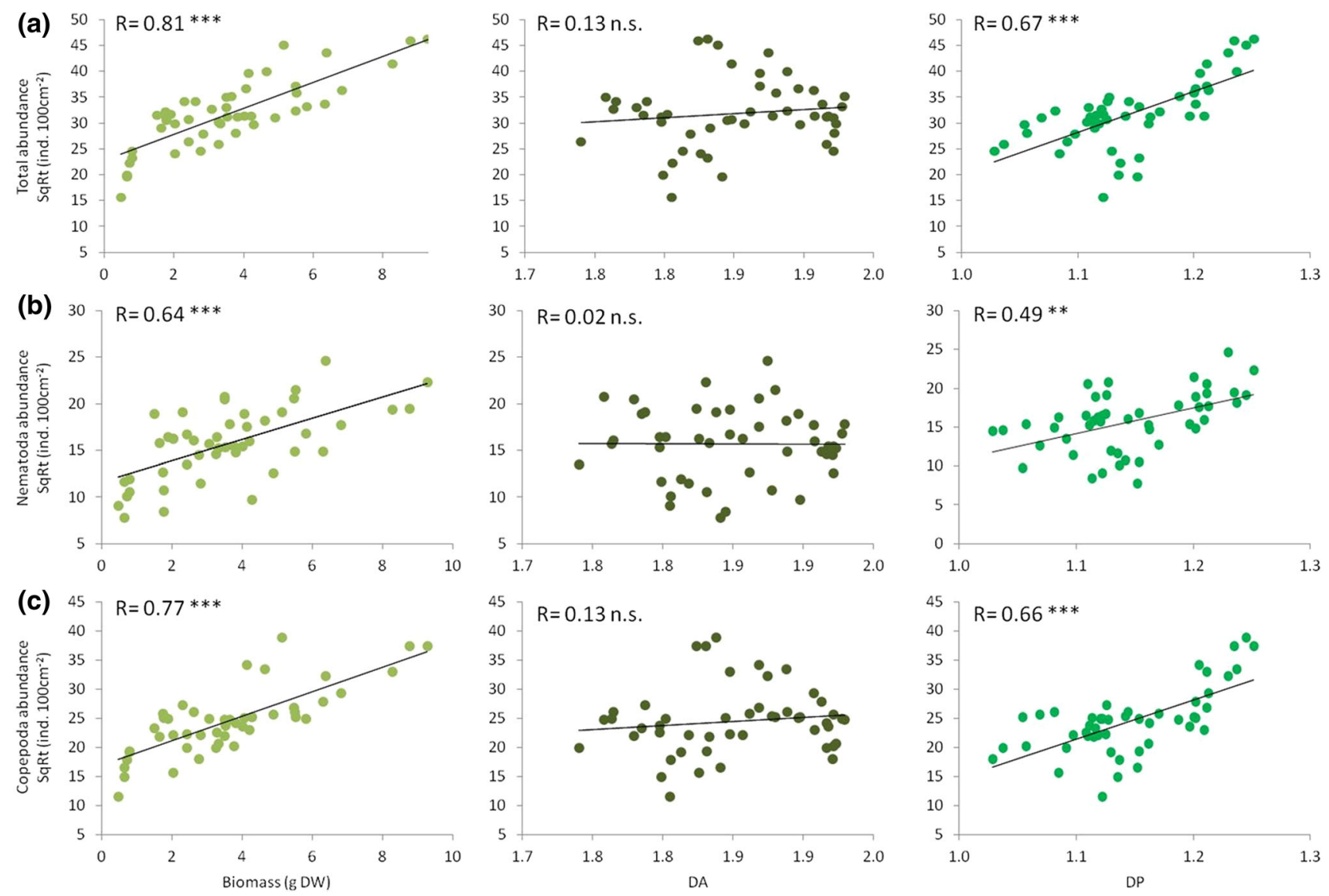

Fig. 6 Relationship between abundance of a total meiofauna, b copepods and c nematodes (square-root-transformed data) and macroalgal habitat size (biomass) and complexity, expressed as

abundant and more dominant in the cuvettes close to the outer margin than in those close to the inner margin. This finding is in agreement with Donnarumma et al. (2014) who found that, in a study on benthic macrofauna associated with Spanish vermetid reefs, the communities on the outer margin were dominated by crustaceans. fractal dimension of area (DA) and perimeter (DP). We reported the value of $R$ and $p(* * *=p<0.001, * *=p<0.01, *=p<0.05$, n.s. = not significant $)$

Macroalgae provide a suitable habitat for a wide range of animal species and can also be deemed as biological "formers" of habitat structure (Jones et al. 1994; GarcíaCharton et al. 2000). At a small spatial scale, marine algae promote complexity of coastal rocky bottoms, providing additional resources such as surface area for attachment, 
shelter, sediment or organic matter traps and food items for invertebrate species (Hayward 1980; Gibbons 1988). The presence of macroalgae on vermetid reefs can increase the availability of spatial niches for meiofaunal organisms, increasing the habitat size and structural complexity (Gibbons 1988; Chemello and Milazzo 2002; Danovaro and Fraschetti 2002). There is evidence that different macroalgae do not support benthic fauna in the same way (Veiga et al. 2014, 2016), and this may depend on several factors such as life cycle, exhibition of chemical defence and algal architecture (Duffy and Hay 1994; Chemello and Milazzo 2002). Macroalgae with a more complex frond architecture usually offer a large number of habitats for colonization of meiofauna (Gibbons 1991), good protection from predators and physical stress and have a high sediment-trapping potential (Coull and Wells 1982; Russo 1997). Therefore, meiofauna associated with complex macroalgae usually show higher abundance and diversity than those associated with less complex macroalgae (Hicks 1980; Gee and Warwick 1994; Frame et al. 2007; Veiga et al. 2016). The architecture of the macroalgae includes measures of the complexity and the size of the habitat (Gee and Warwick 1994; Veiga et al. 2014, 2016). Previous studies of macroalgae have generally included measures of the habitat size (i.e. biomass, surface area, volume) (Taniguchi et al. 2003; Wernberg et al. 2004; Gestoso et al. 2010), but to describe the fine structure and complexity of the habitat, it is useful to estimate the complexity using measures of fractal dimension (Gee and Warwick 1994; McAbendroth et al. 2005; Hooper and Davenport 2006). In the light of this, we investigated the differences among macroalgal architecture by measuring algal biomass (used as a proxy of habitat size) and the fractal dimensions of area and perimeter (used as a proxy of complexity).

However, it is highly expected that the abundance of meiofauna increases with increasing habitat size (Hicks 1980; Arroyo et al. 2004). For this reason to compare meiofauna communities among the different macroalgae on the reefs, we used the algal biomass as the covariate. Veiga et al. (2016) suggested that using this method is better than standardizing by macroalgal biomass because the effect of biomass can be dependent on macroalgal identity. Consistent with this we found that the habitat size significantly influenced the abundance and community composition of meiofauna associated with macroalgae, but its effect was dependent on macroalgal identity. The effect of macroalgal identity could be attributed to differences in their complexity; in fact the studied macroalgae were significantly different in their fractal dimensions (DA and DP).

Our results showed a significant higher total abundance of meiofauna on Cystoseira sp. than on the four remaining macroalgae. Cystoseira spp. are known to be among the most important habitat-forming species of shallow Mediterranean Sea ecosystems and are responsible for the maintenance of abundant and biodiverse faunal and algal assemblages (Chemello and Milazzo 2002; Bianchelli et al. 2016; Bulleri et al. 2002).

Meiofaunal communities associated with sampled macroalgae taxa were dominated by copepods, followed by nematodes, in agreement with other studies (Gibbons 1988; Danovaro and Fraschetti 2002; Pérez-García et al. 2015; Veiga et al. 2016). Copepods are frequently associated with macroalgae, being part of the phytal meiofauna, due to a greater capacity to swim and colonize macroalgae when compared to interstitial forms of meiofauna (Hicks 1986; Ólafsson et al. 2001). The differences observed in meiofaunal community composition among macroalgae were probably the result of the differing abundance of this taxon. In fact the dissimilarities were mostly explained by copepods, found in significantly higher abundance on Cystoseira sp. than the other macroalgae.

Regression analysis, according to previous studies (Hicks 1980; Arroyo et al. 2004; Veiga et al. 2016), showed a significant, positive correlation between algal biomass and abundance of the principal meiofaunal taxa (i.e. copepods and nematodes). However, also the complexity of macroalgae significantly influences the distribution of meiofauna, but only when we considered the DP. In fact, we found a positive correlation between DP and abundance of total meiofauna and of the most abundant taxa (i.e. copepods and nematodes), in contrast to the results that other author found for macrofauna (Veiga et al. 2014; Torres et al. 2015), but in accordance with Veiga et al. (2016).

The DP indicates the degree of convolution of macroalgae edge; high values indicate further division of space at smaller scales (McAbendroth et al. 2005). Small animals, such as meiobenthic organisms, may live associated with parts of a phytal structure that are not utilized by larger animals (i.e. macrofauna) (Veiga et al. 2016); thus, algae with more a complex structure, represented by higher DP values, would be expected to support more small animals than structurally simple algae (Raffaelli et al. 2000; Schmid et al. 2002).

In the light of this the highest meiofaunal abundance on Cystoseira sp. can be explained by its more complex architecture, in terms of both biomass and DP, compared with the other macroalgae, consistent with findings in other studies (Russo 1997; Chemello and Milazzo 2002).

The distribution of macroalgae along the reef could be influenced by hydrodynamics and tidal action that in turn could affect the occurrence and abundance of meiofauna on the different macroalgae. In fact we observed a different macroalgal distribution (\% of coverage) from the inner to the outer zone of the vermetid reefs. The high algal 
coverage in the "cuvette zone" can increase the size and complexity of substrate available for meiofauna. Moreover, the increased coverage of Cystoseira sp. in the outer zone, as well as increasing complexity of this part of the reef, can offer protection from turbulence and desiccation for meiofauna (Gibbons 1988; Danovaro and Fraschetti 2002; Arroyo et al. 2004; Logan et al. 2008).

In the light of these results, we can conclude that vermetid reefs, in particular the "cuvette zone", represent a habitat suitable for the settlement of meiofaunal communities. Meiofaunal organisms living in sediment inside cuvettes appeared to be influenced by physical and hydrodynamic characteristic of the different sections of the reef, showing an increase in abundance from the inner to the outer part of the reef. Moreover, the macroalgae colonizing the reef provide additional substrate for meiofauna organisms increasing the habitat size and complexity. Meiofaunal organisms associated with different macroalgae, living on the investigated vermetid reefs, appeared to be influenced by the algal architecture (in term of habitat size and complexity). The high algal cover in the "cuvette zone" make this zone more sheltered and complex and therefore more suitable for the settlement of meiofaunal organisms, in particular the part near the outer margin where we found more complex macroalgae (i.e. Cystoseira $\mathrm{sp}$ ). These results confirm that vermetid reefs, with their structural complexity, play an important role in structuring and enhancing benthic fauna along coastlines and in facilitating the colonization of organisms in physically stressful environments, such as intertidal habitats. The limited bigeographical distribution of the vermetid reefs in the Mediterranean Sea and the increasing amount of potential anthropogenic threats would highlight the importance of vermetid reefs for conservation purposes. Further studies on meiofauna and nematode diversity might provide information on ecological importance of these bioconstructions useful for planning monitoring and conservation strategies.

Acknowledgements This study was carried out in the frame of the Project "Inventory of the Sicilian marine biodiversity-Creation of a Regional Observatory of the Sicilian Biodiversity (ORBS) and development of monitoring techniques useful for species management and habitat protection" funded by the Dipartimento Regionale dell'Ambiente, Regione Sicilia (PO FESR 2007-2013-Action Line 3.2.1.2).

\section{Compliance with ethical standards}

Conflict of interest On behalf of all authors, the corresponding author states that there is no conflict of interest.

Open Access This article is distributed under the terms of the Creative Commons Attribution 4.0 International License (http://crea tivecommons.org/licenses/by/4.0/), which permits unrestricted use, distribution, and reproduction in any medium, provided you give appropriate credit to the original author(s) and the source, provide a link to the Creative Commons license, and indicate if changes were made.

\section{References}

Anderson MJ (2001) A new method for non-parametric multivariate analysis of variance. Austral Ecol 26:32-46

Anderson MJ, Robinson J (2003) Generalised discriminant analysis based on distances. Aust NZJ Stat 45(3):301-318

Antonioli F, Chemello C, Improta S, Riggio S (1999) Dendropoma lower intertidal reef formations and their palaeoclimatological significance, NW Sicily. Mar Geol 161:155-170

Ape F, Sarà G, Airoldi L, Mancuso F, Mirto S (2017) Influence of environmental factors and biogenic habitats on intertidal meiofauna. Hydrobiologia 807:349-366

Arroyo NL, Maldonado M, Pérez-Portela R, Benito J (2004) Distribution patterns of meiofauna associated with a sublittoral Laminaria bed in the Cantabrian Sea (north-eastern Atlantic). Mar Biol 144:231-242

Attrill MJ, Strong JA, Rowden AA (2000) Are macroinvertebrate communities influenced by seagrass structural complexity? Ecography 23:114-121

Badalamenti F, Chemello R, Gristina M, Riggio S, Toccaceli M (1992) Caratterizzazione delle Piattaforme a Molluschi Vermetidi nella costa tra Capo Gallo ed Isola delle Femmine (PA): area proposta come riserva naturale marina; Oebalia, Suppl. 17:547-549

Balistreri P, Chemello R, Mannino AM (2015) First assessment of the vermetid reefs along the coasts of Favignana Island (Southern Tyrrhenian Sea). Biodivers J 6(1):371-376

Bianchelli S, Pusceddu A, Canese S, Greco S, Danovaro R (2013) High meiofaunal and nematodes diversity around mesophotic coral oases in the Mediterranean Sea. PLoS One 8(6):e66553

Bianchelli S, Pusceddu A, Buschi E, Danovaro R (2016) Trophic status and meiofauna biodiversity in the Northern Adriatic Sea: insights for the assessment of good environmental status. Mar Environ Res 113:18-30

Bulleri F, Benedetti-Cecchi L, Acunto S, Cinelli F, Hawkins SJ (2002) The influence of canopy algae on vertical patterns of distribution of low-shore assemblages on rocky coasts in the northwest Mediterranean. J Exp Mar Biol Ecol 267:89-106

Callaway R, Desroy N, Dubois SF, Fournier J, Frost M, Godet L, Hendrick VJ, Rabaut M (2010) Ephemeral bioengineers or reefbuilding polychaetes: how stable are aggregations of the tube worm Lanice conchilega (Pallas, 1766)? Integr Comp Biol 50:237-250

Cerrano C, Danovaro R, Gambi C, Pusceddu A, Riva A, Schiaparelli S (2010) Gold coral (Savalia savaglia) and gorgonian forests enhance benthic biodiversity and ecosystem functioning in the mesophotic zone. Biodivers Conserv 19(1):153-167

Chemello R, Milazzo M (2002) Effect of algal architecture on associated fauna: some evidence from phytal molluscs. Mar Biol 140(5):981-990

Chemello R, Silenzi S (2011) Vermetid reefs in the Mediterranean Sea as archives of sea-level and surface temperature changes. Chem Ecol 27:121-127

Chemello R, Ciuna I, Pandolfo A, Riggio S (1998) Molluscan assemblages associated to the intertidal vermetid formations: a morpho-funlctional approach. Boll Malacol 33:105-114

Clarke KR (1993) Non parametric multivariate analyses of changes in community structure. Austral J Ecol 18:117-143 
Clarke KR, Warwick RM (1994) Change in marine communities: An approach to statistical analysis and interpretation, 2nd edn. Primer-e Ltd, Plymouth Marine Laboratory, Plymouth, U.K.

Colombo F, Costa V, Dubois SF, Gianguzza P, Mazzola A, Vizzini S (2013) Trophic structure of vermetid reef community: High trophic diversity at small. J Sea Res 77:93-99

Consoli P, Romeo T, Giongrandi U, Andaloro F (2008) Differences among fish assemblages associated with a nearshore vermetid reef and two other rocky habitats along the shores of Cape Milazzo (northern Sicily, central Mediterranean Sea). J Mar Biol Assoc UK 88:401-410

Coull BC, Wells JBJ (1982) Refuges from fish predation: experiments with phytal meiofauna from the New Zealand rocky intertidal. Ecology 64:1599-1609

Danovaro R, Fraschetti S (2002) Meiofaunal vertical zonation on hard bottoms: comparison with soft-bottom meiofauna. Mar Ecol Prog Ser 230:159-169

Danovaro R, Gambi C, Dell'Anno A, Corinaldesi C, Fraschetti S, Vanreusel A, Vincs M, Gooday AJ (2008) Exponential decline of deep-sea ecosystem functioning linked to benthic biodiversity loss. Curr Biol 18(1):1-8

Di Franco A, Graziano M, Franzitta G, Felline S, Chemello R, Milazzo M (2011) Do small marinas drive habitat specific impacts? A case study from Mediterranean Sea. Mar Pollut Bull 62:926-933

Donnarumma L, Terradas M, Appolloni L, Di Stefano F, SánchezLizaso JL, Sandulli R, Russo GF (2014) Associated benthic fauna to the vermetid reefs along the mediterranean spanish coast. Biol Mar Mediterr 21(1):234-235

Dubois S, Retiere C, Olivier F (2002) Biodiversity associated with Sabellaria alveolata (Polychaeta: Sabellariidae) reefs: effects of human disturbances. J Mar Biol Assoc UK 82:817-826

Duffy JE, Hay ME (1994) Herbivore resistance to seaweed chemical defence: the roles of mobility and predation risk. Ecology 72:1286-1298

Frame K, Hunt G, Roy K (2007) Intertidal meiofaunal biodiversity with respect to different algal habitats: a test using phytal ostracodes from Southern California. Hydrobiologia 586:331-342

Franzitta G, Capruzzi E, La Marca EC, Milazzo M, Chemello R (2016) Recruitment patterns in an intertidal species with low dispersal ability: the reef-building Dendropoma cristatum (Biondi, 1859) (Mollusca: Gastropoda). Ital J Zoo 83(3):400-407

García-Charton JA, Williams I, Pérez-Ruzafa A, Milazzo M, Chemello R, Marcos C, Kitsos MS, Koukouras A, Riggio S (2000) Evaluating the ecological effects of Mediterranean marine reserves: habitat, scale and the natural variability of ecosystems. Environ Conserv 27:179-199

Gee JJ, Warwick RM (1994) Metazoan community structure in relation to the fractal dimension of marine macroalgae. Mar Ecol Prog Ser 103:141-150

Gestoso I, Olabarria C, Troncoso JS (2010) Variability of epifaunal assemblages associated with native and invasive macroalgae. Mar Freshwater Res 61:724-731

Gibbons MJ (1988) The impact of sediment accumulations, relative habitat complexity and elevation on rocky shore meiofauna. J Exp Mar Biol Ecol 122:225-241

Gibbons MJ (1991) Rocky shore meiofauna: a brief overview. T Roy Soc S Afr 47:595-603

Goren M, Galil BS (2001) Fish biodiversity in the vermetid reef of Shiqmona (Israel). Mar Ecol 22:369-378

Gutierrez JL, Jones CG, Strayer DL, Iribarne OO (2003) Mollusks as ecosystem engineers: the role of shell production in aquatic habitats. Oikos 101(1):79-90
Hayward PJ (1980) Invertebrate epiphytes of coastal marine algae. In: Price JH, Irvine DEG, Farnham WF (eds) The shore environment. Ecosystems Systematics Association. Academic, London, pp 761-787

Heip C, Vincx M, Vranken G (1985) The ecology of marine nematodes. Aberdeen University Press

Hicks GRF (1980) Structure of phytal harpacticoid copepod assemblages and the influence of habitat complexity and turbidity. J Exp Mar Biol Ecol 44:157-192

Hicks GRF (1986) Distribution and behaviour of meiofaunal copepods inside and outside seagrass beds. Mar Ecol Prog Ser 31:159-170

Hooper GJ, Davenport J (2006) Epifaunal composition and fractal dimensions of intertidal marine macroalgae in relation to emersion. J Mar Biol Assoc UK 86:1297-1304

Jones CG, Lawton JH, Shachak M (1994) Organisms as ecosystem engineers. Oikos 69:373-386

Kostylev VE, Erlandsson J, Ming MJ, Williams GA (2005) The relative importance of habitat complexity and surface area in assessing biodiversity: Fractal application on rocky shores. Ecol Complex 2:272-286

Little C, Williams GA, Trowbridge CD (2009) The biology of rocky shores, 2nd edn. Oxford University Press, New York

Logan D, Townsend KA, Townsend K, Tibbetts IR (2008) Meiofauna sediment relations in leeward slope turf algae of Heron Island reef. Hydrobiologia 610:269-276

Mannino AM (1992) Studio fitosociologico della vegetazione mesolitorale a "Lithophyllum lichenoides" PHILIPPI (Rhodophyceae, Corallinales). Nat sicil:3-25

Mare MF (1942) A study of marine benthic community whit special reference to the micro-organism. J Mar Biol Assoc UK 25:517-554

May RM (1972) Will a large complex system be stable? Nature 238:413-414

McAbendroth L, Ramsay PM, Foggo A, Rundle SD, Bilton DT (2005) Does macrophyte fractal complexity drive in vertebrate diversity, biomass and body size distributions? Oikos 111:279-290

McArdle BH, Anderson MJ (2001) Fitting multivariate models to community data: a comment on distance-based redundancy analysis. Ecology 82:290-297

Milazzo M, Fine M, La Marca EC, Alessi C, Chemello C (2016). Drawing the line at neglected marine ecosystems: ecology of vermetid reefs in a changing ocean. In Marine animal forests, pp: $1-23$

Molinier R, Picard J (1953) Notes biologiques a propos d'un voyage d'étude sur les cotes de Sicile. Ann Inst Oceanogr (Paris) 28:163-188

Ólafsson E, Ingólfsson A, Steinarsdóttir MB (2001) Harpacticoid copepod communities of floating seaweed: controlling factors and implications for dispersal. Hydrobiologia 453:189-200

Pérez-García JA, Ruiz-Abierno A, Armenteros M (2015) Does morphology of host marine macroalgae drive the ecological structure of epiphytic meiofauna. J Mar Biol Oceanogr 4:2

Raffaelli D, Hall S, Emes C, Manly B (2000) Constraints on body size distributions: an experimental approach using a small-scale system. Oecologia 122:389-398

Rasband WS (1997) Image J. U. S.Natl. Inst. Of Health, Bethesda (MD). http://rsb.info.nih.gov/ij/

Russo AR (1997) Epifauna living on sublittoral seaweeds around Cyprus. Hydrobiologia 344:169-179

Safriel UN (1966) Recent vermetid formation on the Mediterranean shore of Israel. Proc Malac Soc Lond 37:27-34

Safriel UN, Ben-Eliahu MN (1991) The influence of habitat structure and environmental stability on the species diversity of 
polychaetes in vermetid reefs in: Bell S.S., McCoy D.E. and Mushinsy R. (Eds). Habitat structure, pp 349-372

Sarà G, Milanese M, Prusina I, Sarà A, Angel DL, Glamuzina B, Nitzan T, Freeman S, Rinaldi A, Palmeri V, Montalto V, Lo Martire M, Gianguzza P, Arizza V, Lo Brutto S, De Pirro M, Helmuth B, Murray J, De Cantis S, Williams GA (2014) The impact of climate change on Mediterranean intertidal communities: losses in coastal ecosystem integrity and services. Reg Environ Change 14(1):5-17

Schmid PE, Tokeshi M, Schmid-Araya JM (2002) Scaling in stream communities. P Roy Soc Lond B Bio 269:2587-2594

Taniguchi H, Nakano S, Tokeshi M (2003) Influences of habitat complexity on the diversity and abundance of epiphytic invertebrates on plants. Freshwater Biol 48:718-728

Torres AC, Veiga P, Rubal M, Sousa-Pinto I (2015) The role of annual macroalgal morphology in driving its epifaunal assemblages. J Exp Mar Biol Ecol 464:96-106
Veiga P, Rubal M, Sousa-Pinto I (2014) Structural complexity of macroalgae influences epifaunal assemblages associated with native and invasive species. Mar Environ Res 101:115-123

Veiga P, Sousa-Pinto I, Rubal M (2016) Meiofaunal assemblages associated with native and non-indigenous macroalgae. Cont Shelf Res 123:1-8

Vizzini S, Colombo F, Costa V, Mazzola M (2012) Contribution of planktonic and benthic food sources to the diet of the reefforming vermetid gastropod Dendropoma petraeum in the western Mediterranean. Estuar Coast Shelf Sci 96:262-267

Wernberg T, Thomsen MS, Staehr PA, Pedersen MF (2004) Epibiota communities of the introduced and indigenous macroalgal relatives Sargassum muticum and Halidrys siliquosa in Limfjorden (Denmark). Helgoland Mar Res 58:154-161 